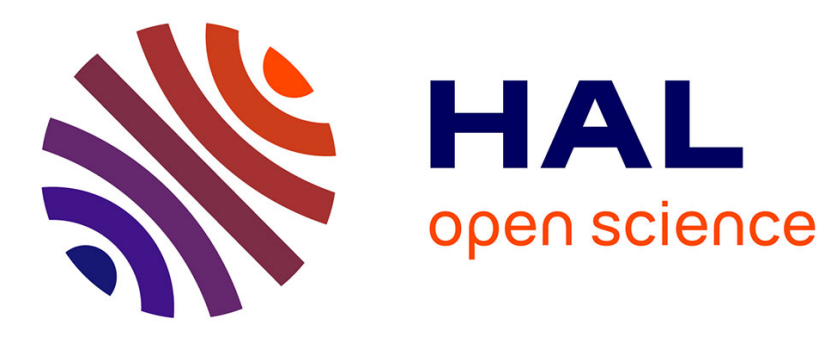

\title{
The development and internal assessment of a high-resolution, non-proprietary, stereo-photogrammetric setup for hydraulic experiments
}

Stéphane Bertin, Heide Friedrich, Edwin Chan, Patrice Delmas

\section{- To cite this version:}

Stéphane Bertin, Heide Friedrich, Edwin Chan, Patrice Delmas. The development and internal assessment of a high-resolution, non-proprietary, stereo-photogrammetric setup for hydraulic experiments. 27th International Conference Image and Vision Computing New Zealand, Nov 2012, Dunedin, New Zealand. 10.1145/2425836.2425933 . hal-03470835

\section{HAL Id: hal-03470835 \\ https://hal.science/hal-03470835}

Submitted on 21 Dec 2021

HAL is a multi-disciplinary open access archive for the deposit and dissemination of scientific research documents, whether they are published or not. The documents may come from teaching and research institutions in France or abroad, or from public or private research centers.
L'archive ouverte pluridisciplinaire $\mathbf{H A L}$, est destinée au dépôt et à la diffusion de documents scientifiques de niveau recherche, publiés ou non, émanant des établissements d'enseignement et de recherche français ou étrangers, des laboratoires publics ou privés. 


\section{The development and internal assessment of a high- resolution, non-proprietary, stereo-photogrammetric setup for hydraulic experiments}

\author{
Stéphane Bertin ${ }^{1}$ \\ Heide Friedrich ${ }^{1}$ \\ Department of Civil and Environmental Engineering \\ The University of Auckland \\ Private Bag 92019, Auckland 1142 \\ New Zealand \\ sber081@aucklanduni.ac.nz \\ h.friedrich@auckland.ac.nz
}

\author{
Edwin Chan² \\ Department of Computer Science \\ The University of Auckland \\ Private Bag 92019, Auckland 1142 \\ New Zealand \\ p.delmas@auckland.ac.nz \\ ycha171@aucklanduni.ac.nz
}

Patrice Delmas ${ }^{2}$

\begin{abstract}
Remote sensing of riverine gravel-beds has been shown to be fundamental to derive a theoretically driven definition of the hydraulic roughness and to understand the complex processes at the sediment-water interface. Commonly, 2D gravel-bed topography was recorded and analyzed, and only more recently technology allowed the measurement of high-resolution 3D Digital Elevation Models (DEMs). Equipment to do so is limited to Terrestrial LaserScanners (TLS) and proprietary stereo-photogrammetric systems and associated commercial software. Obtaining 3D DEMs of the gravel-bed allows the use of advanced statistical functions of riverbed elevations, like Probability Distribution Functions (PDFs) and structure functions, to characterize the spatial and temporal structural development of the riverbed surface. The promise of quick high-resolution data acquisitions, obtained with digital closerange stereo-photogrammetry, which can be employed at various locations, warrants detailed research into this area. In this paper we present the development of a high-resolution, non-proprietary stereo-photogrammetric setup, to be used for hydraulic experiments aimed at gravel-bed roughness characterization. Based on the quantitative assessment of the calibration process and stereo rectification of the images, means to evaluate the reliability of the system are described. It is shown that the extraction of the internal orientation of the two cameras and the external orientation of the stereo setup, as well as the rectification of the images to epipolar geometry, are crucial steps to successfully match corresponding pixels and obtain high-quality DEMs of a gravel-bed. Finally, surface plots of the measured gravel-bed topography are presented, showing how improvements are reflected in the quality of the DEMs.
\end{abstract}

\section{Categories and Subject Descriptors}

I.2.10 [Vision and Scene Understanding]: 3D/stereo scene analysis, Modeling and recovery of physical attributes.

\section{General Terms}

Measurement, Reliability, Experimentation, Verification.

\section{Keywords}

Close-range stereo-photogrammetry, riverine gravel-bed, roughness, Digital Elevation Models, internal assessment.

\section{INTRODUCTION}

In the absence of means to record riverbed topography, hydraulic roughness has long been associated with a characteristic grain size of the sediment particles constituting the riverbed surface. In gravel-bed rivers, it was found experimentally that, the size of the intermediate axis of the gravel particles for which $84 \%$ are smaller, multiplied by a constant, can fit in flow resistance equations and give relatively accurate estimates of the average velocity of the river flow in some situations, [8]. Percentiles of the Grain Size Distribution (GSD) are generally determined by size-sieving, counting and weighing of the gravel particles lying on the riverbed surface. More recently, digital methods allowed the automation of the process, [12]. However, the characteristic grain size approach lacks in theoretical justifications and failed at explaining important fluvial-geomorphologic processes, [2,16,18].

The idea that detailed 3D measurements of the riverbed surface could characterize the hydraulic roughness completely from a topographic point of view is more legitimate. Firstly, it enables a vertical roughness length to be related to the elevations of the particles that protrude into the flow and create resistance $[16,18,19]$. Additionally, new information on the structure of the riverbed surface can be recorded, such as the degree of complexity of the particles organisation, the orientation and angle of the gravel particles, which are all attributed to affect the flow pattern, $[7,9,14,16]$.

In recent studies, high-resolution 3D Digital Elevation Models (DEMs) of the gravel-bed surface in laboratory flumes were used with Probability Distribution Functions (PDFs) and 2D secondorder structure functions of bed elevations to provide the analytical basis for the understanding of how water-worked gravel-beds adapt to the water flow through the armoring process, $[1,15]$.

Generally, hydraulic research takes place in a challenging environment, especially for remote sensing applications of bed topography. More work must be devoted to the development of adequate measurement techniques to be able to use them efficiently in natural river environments. In the next section, a quick overview of the photogrammetric systems and laser-scanners employed in past research is presented. This overview is used to highlight the improvements of our developed setup, as presented in this paper. 


\subsection{Historical review of areal bed topography measurements}

Applications of close-range stereo-photogrammetry for roughness characterization research were undertaken with both simulated sediment beds in laboratories and natural gravel-beds, [5,6]. [7] did successfully obtain through-water photogrammetric measurements of a riverbed. These studies employed non-digital semimetric cameras and high-definition scanners. Hardcopies of the gravel-bed stereo images were transformed into softcopies, from which the automatic extraction of the DEMs was performed using the Photogrammetric module OrthoMAX by Erdas Imagine ${ }^{\circledR}$. Additionally, targets were glued onto the riverbed surface, and their 3D positioning was estimated with Leica T1610 co-axial total stations. This enabled the interior and exterior orientation of the cameras to be extracted and the quality of the stereo process to be evaluated. A detailed methodology for counting and managing errors was presented. [5] particularly pointed out the need for a control check of the DEMs before statistical roughness analysis. In addition, the studies highlighted the difficulty to compute the standard error in vertical elevation, because errors also arose from the localization of the targets using total stations.

Photogrammetry, as a very versatile technique, was involved in other hydraulic experiments, which for example require a large surface coverage or repeated measurements in a short time span. In [20], the sedimentation processes in a braided stream were studied in the laboratory and the volumetric rate of sediment transport was determined by differentiating successive DEMs. [17], used twomedia photogrammetry, air and water, measuring the $3 \mathrm{D}$ temporal evolution of a scour hole at a bridge pier in the laboratory, with stereo pairs taken every second. These two studies used non-metric digital cameras, and commercial software, OrthoMAX and Leica Photogrammetry Suite (LPS) by Leica Geosystems, for the photogrammetric process.

Although the use of photogrammetric means becomes more common, most topographic measurements of gravel-beds were undertaken using time-of-flight Terrestrial Laser-Scanners (TLS) of various types, $[1,11,13,14,15,19]$. This certainly traduces that laser altimeters can be employed with ease in detailed microtopographic measurements and provide a high accuracy without the need to assess in detail the DEM accuracy. TLS were also successfully employed in field-based experiments, [13,14], but unlike stereo-photogrammetry, no submerged measurements could be done because of the laser red beam. Additionally, the time required to survey a test section, and sometimes the size of the laser footprint, were limitations to high-resolution and repeated measurements, as in [1].

\subsection{Objective}

In this study a high-resolution, non-proprietary, stereophotogrammetric system, to be used in hydraulic experiments aimed at gravel-bed roughness characterization, and means to evaluate its accuracy, are presented. In the first part, the experimental setup is described in detail, as well as the methods employed for camera calibration, epipolar rectification, and automatic stereo matching. The results are discussed by visual examination of DEMs obtained at two development phases, at the beginning of the research project, and at what the system is able to obtain at present. Detailed analysis shows that accurate calibration and precise stereo rectification of image pairs, are crucial steps to obtain quality DEMS of a gravel-bed.

\section{EXPERIMENTAL CONDITIONS}

\subsection{Experimental setup}

The DEMs presented in this study use experimental data sets obtained in a 19-m long, 0.45-m wide and 0.5-m deep hydraulic flume available in the Fluid Mechanics Laboratory of The University of Auckland. The overall test section over which photogrammetric measurements were undertaken comprised a 955$\mathrm{mm}$ long, full-width, vertically adjustable recess. Both the upstream and downstream bed sections surrounding the recess were artificially roughened to help obtaining fully developed flow conditions (Figure 1). Initially, the recess was filled with randomly mixed, natural, graded and rounded sediment with D50 $=7-\mathrm{mm}$ and a maximum gravel size of D98 $=50-\mathrm{mm}$ and the surface was flattened to a thickness of $10-\mathrm{cm}$. The gravel-bed was then waterworked and naturally armored over four hours at a constant flow rate of $\mathrm{Q}=66-\mathrm{L} / \mathrm{s}$ and a constant water depth of $20-\mathrm{cm}$. Finally, the flume was drained to survey the bed surface.

To enable the topography of the water-worked bed to be measured, the test section was equipped with a special carriage for stereophotogrammetry equipment, which could easily be moved along the flume. Two cameras were mounted on the frame at adjustable heights. The mounting bar for the cameras could be rotated at 90 degrees, enabling stereo images to be taken vertically from above for the gravel-bed and horizontally for the calibration checkerboard positioned outside the flume. This way, camera calibration could be done on site, under the same conditions, obviating the need to move the stereo setup, which could affect the calibration parameters. This method also removes the need for photocontrolled targets.

The lighting was set up with two 1-m long neon lights, installed next to the transparent sides of the flume, along the test section. A self-made light diffuser was used and consisted of thin sheets of white Plexiglas applied between the neon lights and the flume glass walls. This permitted a dim and homogeneous light to be obtained over the test section, with very little light reflections from the gravel particles.

\subsection{Photogrammetric measurement of gravel- bed topography}

The stereo-photogrammetric setup used in this study is composed of two Nikon D90 digital single lens-reflex consumer cameras, with a 20-mm lens and a 5.5- $\mu \mathrm{m}$ pixel size $p$ on the CCD sensor (12.3megapixel). The two cameras were mounted along the flow direction 1.1-m above the flume, with a $300-\mathrm{mm}$ baseline $b$ between them (see figure 1).

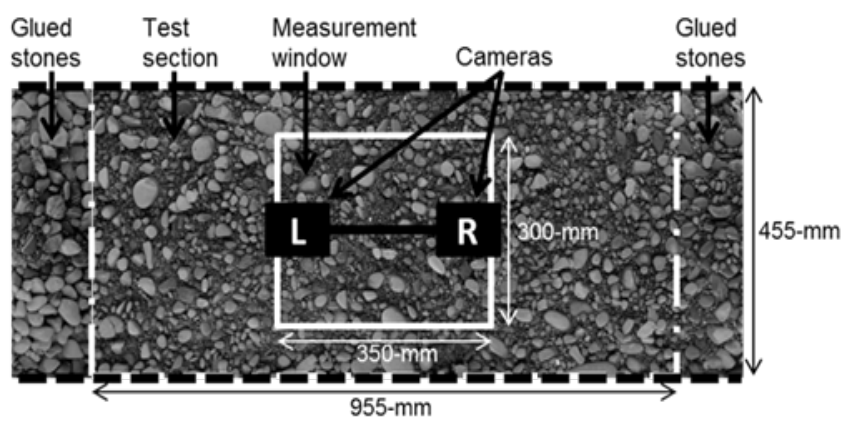

Figure 1 Gravel-bed and measurement window.

The design of the stereo-setup was determined to obtain a Common Field of View (CFoV) of the two cameras, where elevation data can be obtained, of the size of the full test section. This meant that at 
the cameras' elevation required, the setup would provide a $\mathrm{CFoV}$ with the horizontal extent larger than the vertical extent (see Figure 2), so that cameras were aligned in the flow direction and lowered at maximum to a distance from the sediment bed of $1.1-\mathrm{m}$. The horizontal resolution with which photogrammetric measurements were obtained of the riverbed surface was thus optimized and calculated to be $0.16-\mathrm{mm} / \mathrm{pixel}$, or 39pixels $/ \mathrm{mm}^{2}$.

Before taking photographs of the gravel-bed, the settings for both cameras were manually adjusted to be identical (shutter speed of 1.3-s, F/20 aperture, ISO 200) and manually focused on the bed surface. Attention was taken to obtain similar left and right photographs, with a good exposure and contrast, to facilitate the stereo-matching.

The independent calibration of the two cameras and stereo

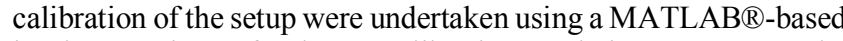
implementation of Zhang calibration technique, [4,21]. The intrinsic and extrinsic parameters of the two cameras are determined by solving homography between the cameras and a planar target, the calibration checkerboard. For accuracy, the checkerboard was always photographed in more than 20 positions (all degrees of freedom were used) covering most of the CFoV, with the checkerboard at distances from the cameras embracing $1.1-\mathrm{m}$, the distance at which the gravel-bed was photographed. The calibration checkerboard was printed on A3 paper and glued on a flat inflexible plate. It had an orthogonal grid with alternating black and white $20-\mathrm{mm}$ squares, with 16 horizontal squares and 12 vertical squares. Radial and tangential lens distortions of the two cameras were modeled with a sixth-order polynomial through optimization search after obtaining closed-form estimates of other calibration parameters. Still using Bouguet's toolbox for MATLAB $R$, the two cameras were calibrated in stereo configuration, through the optimization of the parameters with the translation between the cameras (or baseline) as a constraint.

Stereo calibration allows the stereo pairs to be rectified as close as possible to epipolar geometry, where two corresponding points are aligned on the same scan line, and thus simplifying the stereo matching process. In the stereo rectification process, the projection equations between the two cameras are solved, which gives a close form transformation matrix to epipolar geometry. Additionally, lens distortion is removed.

Stereo matching of the corresponding pixels was undertaken on the rectified images, using [10]'s Symmetric Dynamic Programming Stereo-matching (SDPS) algorithm. The disparity range associated with the distances from the cameras to the gravel-bed (exaggerated minimum and maximum distances), 850 to 1050-pixels was used as an input parameter in the program. The result is a depth map, with a minimum measurable disparity rounded to one pixel, which corresponds to a minimum distinguishable vertical distance on the gravel-bed (or best accuracy achievable) of 1-mm. From the depth map and the calibration results, a point cloud containing the $3 \mathrm{D}$ coordinates of all measured points on the gravel-bed $(5,200,000$ million points) was extracted and finally opened with MATLAB ${ }^{\circledR}$ to represent the gravel-bed as a 3D DEM. For producing a surface plot with MATLAB $R$, the data was reduced to 832,000 points, changing the horizontal resolution from $0.16-\mathrm{mm}$ to $1-\mathrm{mm}$, and plotted on an orthogonal grid.

In this study, a high-resolution DEM obtained using the methodology presented above is compared to a DEM presented in
[3] and obtained early in the development of the technique. The comparison is done over a gravel-bed patch of size $350-\mathrm{mm}$ downstream and 300-mm transverse, a size considered sufficient for subsequent work on the roughness characterization.

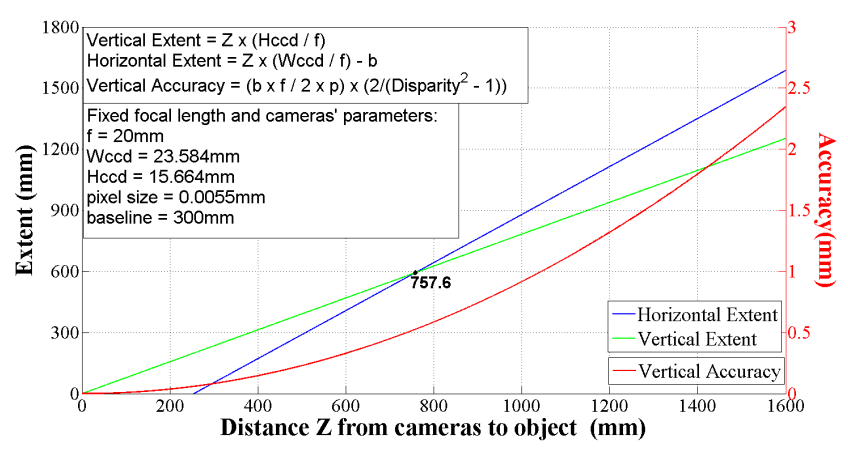

Figure 2 Definition of the photogrammetric setup.

\section{RESULTS}

\subsection{Digital Elevation Models (DEMs)}

The visual examination of Figure 3 shows that the two DEMs obtained at different stages of the research project development are significantly different, although measuring a similar gravel-bed.

The DEM in Figure 3a shows numerous measurement spikes that could not be suppressed with data post-processing. Measurement imprecisions were addressed by detecting outliers, comparing their neighbors' elevation, plus or minus 3-mm, and replace outliers by the average elevation of the four closest neighbors. This noise significantly alters the quality of the DEM, and it was found that statistical roughness analysis cannot be employed. Even the bigger gravel particles are not correctly depicted. In 2011, colored gravel particles were used and it was concluded that the presence of substantial light reflection negatively influenced the DEM recording.

The DEM in Figure 3b correctly represents the shape of the particles, even the one of size smaller than $1-\mathrm{cm}$. The particles contours still display jumps, which can be attributed to the use of a fine orthogonal grid and the discrete nature of integer disparities returned by the depth map.

\subsection{Calibration assessment}

The internal reliability of the photogrammetric process was first evaluated on the calibration results. After independent calibration of the cameras, the interior orientation of the two cameras is estimated. The positions/orientations of the left and right camera are defined with respect to the checkerboard. The calibration results are then used to reproject the estimated corners of the checkerboard from the cameras' optical center on the different calibration images.

The reprojection error, defined as the difference in pixel coordinates between the estimated corners and the actual corners (found with the subpixel accurate corner detection algorithm), was used as an indicator of the accuracy and validity of the calibration results. Figure 4 shows clearly that the reprojection error significantly diminished between the two applications. Initially, the reprojection error obtained in [3] was between -7 and 7 pixels. With the improved methodology presented herewith, the calibration results show a reprojection error ranging between -1 

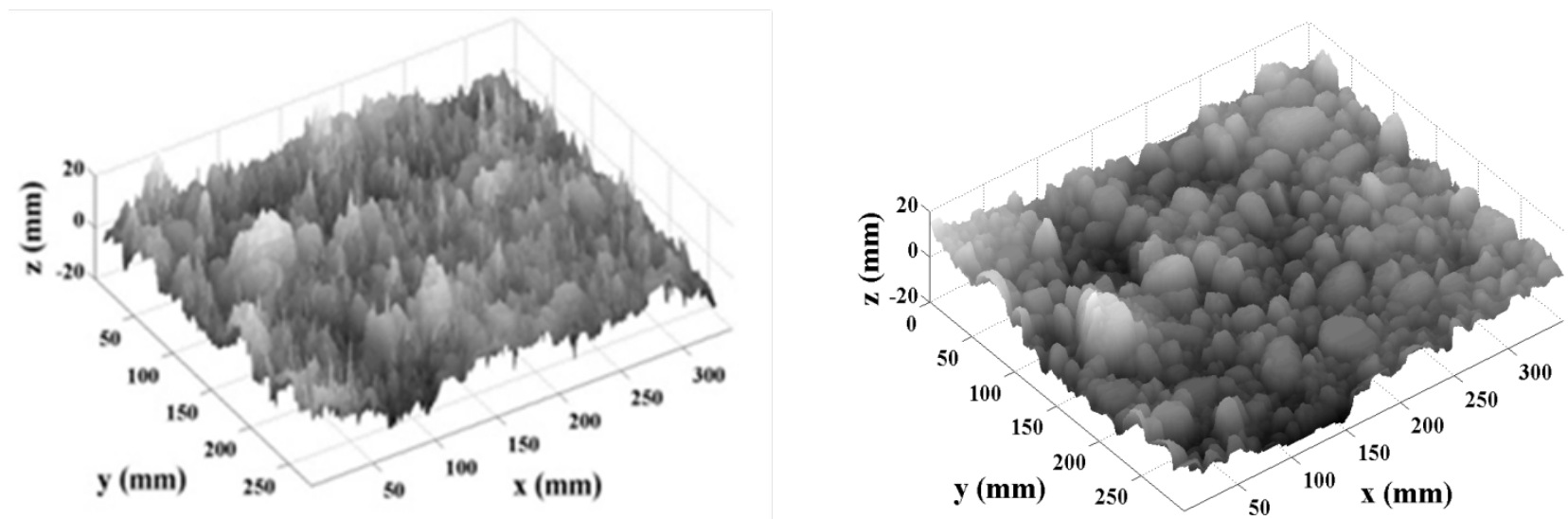

Figure 3 DEMs of 350-mm downstream (x) by 300-mm transverse (y) gravel-bed samples (left) presented in [3] and (right) obtained with the methodology presented herewith.

and 1 pixel, traducing a six-fold improvement in the calibration accuracy.

It was also interesting to plot selected statistics of the reprojection error for each calibration image. This representation helps to identify calibration images, which fail to accurately estimate the calibration results. Depending on the reason of failure, discarding some images in the calibration process may improve the overall results. During testing of the methodology, this is easily implemented for both the right and left image, and both directions $\mathrm{x}$ and $\mathrm{y}$.

However, we do not present these graphs here. Instead, Table 1 summarizes the selected statistical parameters describing the reprojection error for both left and right images, in $\mathrm{x}$ and $\mathrm{y}$ directions.

\subsection{Rectification assessment}

The precision with which stereo pairs were rectified to epipolar geometry was also assessed. This was done by using the corner

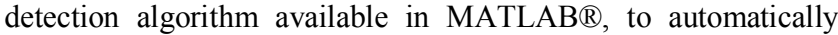
detect the checkerboard corners over all the rectified images. The vertical position of the corners was then compared between the left and right images. For images perfectly rectified to epipolar geometry, the corresponding corners should be at the same vertical coordinates, and the rectification error, defined as the difference in vertical coordinates between corresponding corners, should be zero.

Similarly to the calibration assessment, the rectification error can be represented over all the calibration images retained for the

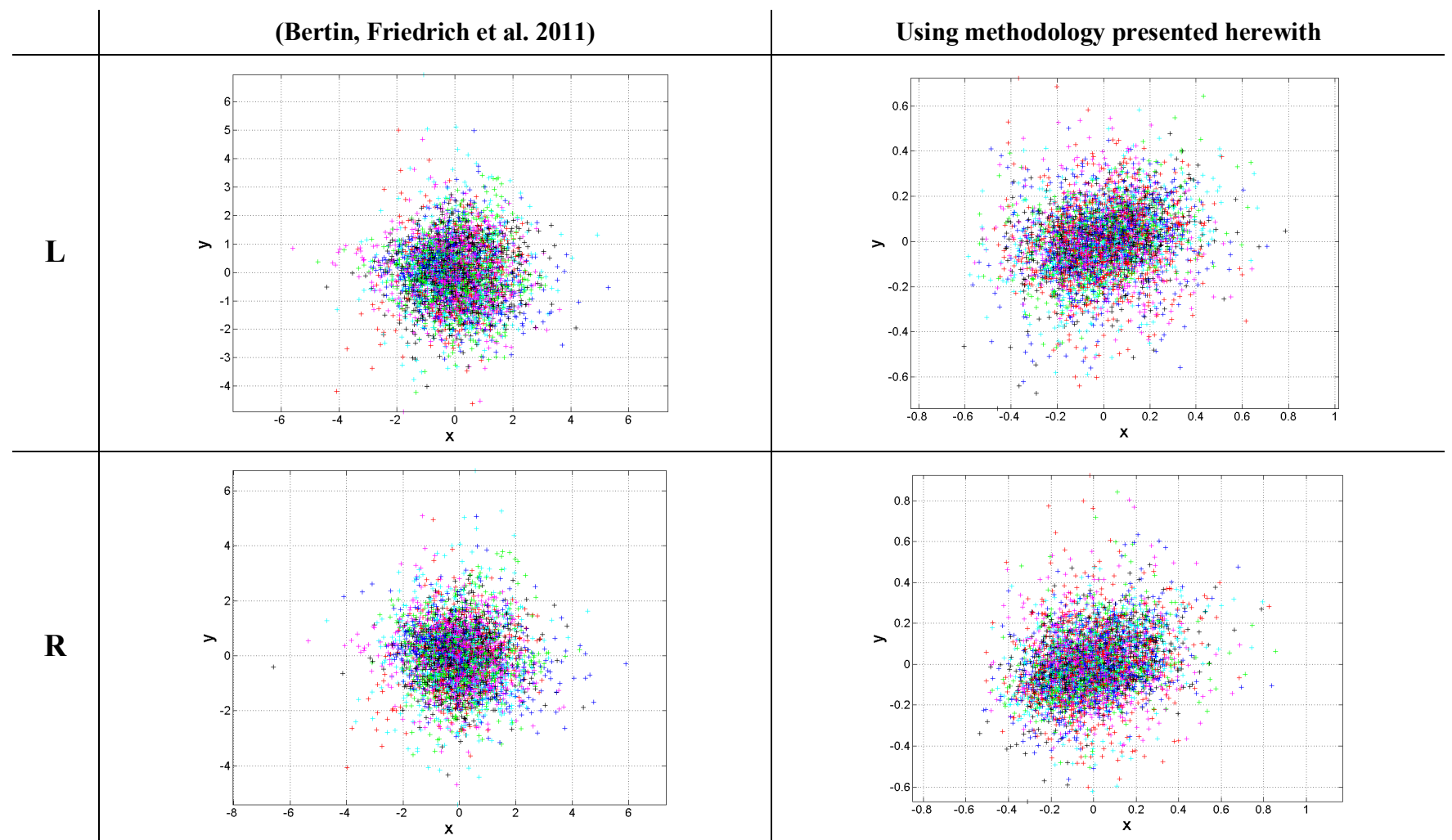

Figure 4 Reprojection error in pixel calculated for the Left and Right camera over all the checkerboard corners on all calibration images, as presented by Bouguet's calibration toolbox for MATLAB®. 
Table 1 Summary of the reprojection error.

\begin{tabular}{|c|c|c|c|c|}
\hline & \multicolumn{2}{|c|}{ (Bertin, Friedrich et al. 2011) } & \multicolumn{2}{c|}{ Using methodology presented above } \\
\hline & $\begin{array}{c}\text { Mean reprojection } \\
\text { error (absolute, pixels) }\end{array}$ & $\begin{array}{c}\text { Reprojection error } \\
\text { standard deviation } \\
\text { (signed, pixels) }\end{array}$ & $\begin{array}{c}\text { Mean reprojection } \\
\text { error (absolute, pixels) }\end{array}$ & $\begin{array}{c}\text { Reprojection error } \\
\text { standard deviation } \\
\text { (signed, pixels) }\end{array}$ \\
\hline $\begin{array}{c}\text { Left-hand image } \\
\text { Along X }\end{array}$ & 0.8943 & 1.1498 & 0.1484 & 0.1865 \\
\hline $\begin{array}{c}\text { Left-hand image } \\
\text { Along Y }\end{array}$ & 0.8879 & 1.1419 & 0.1174 & 0.1556 \\
\hline $\begin{array}{c}\text { Right-hand image } \\
\text { Along X }\end{array}$ & 0.8934 & 1.1624 & 0.1505 & 0.1892 \\
\hline $\begin{array}{c}\text { Right-hand image } \\
\text { Along Y }\end{array}$ & 0.8741 & 1.1501 & 0.1242 & 0.1638 \\
\hline
\end{tabular}

process, which helps deciding if some images should be discarded for better results. In this paper, another plot is presented, which combines the rectification errors, represented by quivers of lengths proportional to the rectification error, obtained over all the rectified images (Figure 5). This graph gives an overview of the coverage of the $\mathrm{CFoV}$ by the checkerboard.

Similarly to the reprojection error, the rectification error is very different between the two applications (Table 2). With the presented setup, the obtained improvement is of the order of 10 . Inaccurate calibration results tend to be reflected, and amplified, in the rectification.

\section{DISCUSSION AND CONCLUSION}

In this paper, the development of a high-resolution, nonproprietary, stereo-photogrammetric system for hydraulic measurements of riverine gravel-beds is presented as well as means to assess the reliability of the obtained DEMs.

The technique developed defers greatly from previous applications of photogrammetric measurements in hydraulic experiments, which generally relied on semimetric cameras and photogrammetric commercial software. Additionally, previous research relied on photo-controlled targets by a Leica Total Station, to be able to assess the accuracy of the photogrammetric measurements. In our study, two digital consumer cameras were employed to take high-definition stereo photographs of a grave-bed in a laboratory flume, and the photogrammetric process (calibration, stereo rectification, stereo matching) was based on available methods. The setup presented enables high-quality DEMs with a $0.16-\mathrm{mm}$ horizontal measurement resolution and $1-\mathrm{mm}$ theoretical vertical accuracy to be obtained over a 955 x $455-\mathrm{mm}$ test section, which improves substantially on previous obtained results. However, the condition of success was to ensure that calibration and stereo rectification of the original images to epipolar geometry are well executed with minimum reprojection and

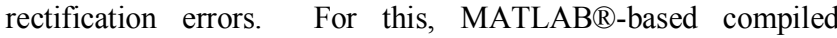
programs were used to characterize the difference in pixel coordinates between corners of the checkerboard as detected by the corner detection algorithm and the corners as estimated with the calibration results. A MATLAB ${ }^{\circ}$ program also computed the difference in pixel coordinates between corresponding corners in the rectified images. This method for internal assessment of the stereo-photogrammetric setup, based on the calibration photographs of the checkerboard, is expected to be representative of the internal errors on the rectified images of the gravel-bed, from which DEMs are obtained. This removes the need to place fixed targets on the gravel-bed to determine their 3D locations with additional instruments, which would risk disturbing the experiments. An internal assessment based on the calibration images is representative of the internal errors on the gravel-bed at the condition that no change takes place between obtaining calibration images and obtaining gravel-bed record. In light of the results, sub-pixel reprojection and rectification errors are important to obtain high-quality DEMs of a gravel-bed.
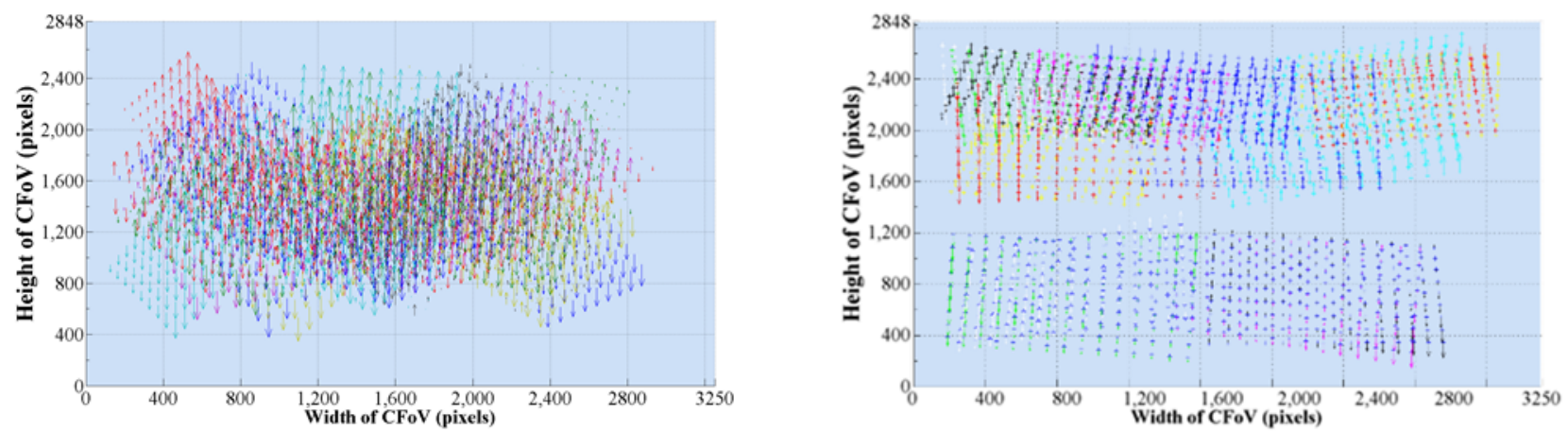

Figure 5 Rectification error in pixel, calculated over all the checkerboard corners for (left) the setup used in [3] and (right) the setup described in this paper. 
Table 2 Summary of the rectification error.

\begin{tabular}{|c|c|c|}
\hline & (Bertin, Friedrich et al. 2011) & Using methodology presented above \\
\hline $\begin{array}{c}\text { Mean rectification error } \\
\text { (absolute, pixels) }\end{array}$ & 1.0067 & 0.0785 \\
\hline $\begin{array}{c}\text { Maximum rectification error } \\
\text { (absolute, pixels) }\end{array}$ & 5.9437 & 0.5167 \\
\hline $\begin{array}{c}\text { Rectification error standard } \\
\text { deviation (absolute, pixels) }\end{array}$ & 0.1459 & 0.0673 \\
\hline
\end{tabular}

The visualisation of the DEMs highlights the need for more testing on the effect of grid size, to understand the restrictions on the finest and coarsest grid usable for data representation and roughness analysis. Also, it is supposed that a convenient way to evaluate the external accuracy of the DEMs would be to compare their elevation with a ground truth. Other instruments, even accurate like laserscanners, result in measurement errors and thus make it difficult to estimate exactly the standard error of photogrammetric measurements. A 3D model of a gravel-bed sample, whose elevation data are known, would provide such a ground truth and is in preparation for the next testing phase of our methodology.

\section{ACKNOWLEDGMENTS}

Our thanks go to the laboratory technicians of the Fluid Mechanics laboratory of the University of Auckland, Geoff Kirby and Jim Luo, who helped in preparing the experimental setup.

The study is partly funded by The University of Auckland CrossFaculty Research Initiatives Fund (CFRIF).

\section{REFERENCES}

[1] Aberle, J. and V. Nikora (2006). "Statistical properties of armored gravel bed surfaces." Water Resources Research 42(11): 11 .

[2] Bergeron, N. (1996). "Scale-space analysis of stream-bed roughness in coarse gravel-bed streams." Mathematical Geology 28(5): 537-561.

[3] Bertin, S., H. Friedrich, et al. (2011). Evaluating the use of stereo-photogrammetry for gravel-bed roughness analysis. International Vision and Computing New Zealand. Auckland, New Zealand: 41-46.

[4] Bouguet, J.-Y. and P. Perona (1998). Camera Calibration from Points and Lines in Dual-Space Geometry. Technical report, California Institute of Technology.

[5] Butler, J. B., S. N. Lane, et al. (1998). "Assessment of Dem Quality for Characterizing Surface Roughness Using Close Range Digital Photogrammetry." The Photogrammetric Record 16(92): 271-291.

[6] Butler, J. B., S. N. Lane, et al. (2001). "Characterization of the structure of river-bed gravels using two-dimensional fractal analysis." Mathematical Geology 33(3): 301-330.

[7] Butler, J. B., S. N. Lane, et al. (2002). "Through-Water Close Range Digital Photogrammetry in Flume and Field Environments." The Photogrammetric Record 17(99): 419439.

[8] Clifford, N., Robert, A., Richards, K. (1992). "Estimation of flow resistance in gravel-bedded rivers a physical explanation of the multiplier of roughness length." Earth. Surf. Proc. Land. 17(2): 111-126.

[9] Cooper, J. R. and S. J. Tait (2009). "Water-worked gravel beds in laboratory flumes - a natural analogue?" Earth Surface Processes and Landforms 34(3): 384-397.

[10] Gimel'farb, G. (2002). "Probabilistic regularisation and symmetry in binocular dynamic programming stereo." Pattern Recognition Letters 23(4): 431-442.

[11] Goring, D. G., V. I. Nikora, et al. (1999). "Analysis of the texture of gravel-beds using 2-D structure functions." I.A.H.R. Symposium on River, Coastal and Esturine Morphodynamics 2: 111-120.

[12] Heays, K. (2012). Cluster formation and stream-bed armouring : a photogrammetric study. Department of Civil and Environmental Engineering. Auckland, The University of Auckland. PhD.

[13] Heritage, G. L. and D. J. Milan (2009). "Terrestrial Laser Scanning of grain roughness in a gravel-bed river." Geomorphology 113(1-2): 4-11.

[14] Hodge, R., J. Brasington, et al. (2009). "Analysing laser scanned digital terrain models of gravel bed surfaces: linking morphology to sediment transport processes and hydraulics." Sedimentology 56(7): 2024-2043.

[15] Mao, L., J. R. Cooper, et al. (2011). "Grain size and topographical differences between static and mobile armour layers." Earth Surface Processes and Landforms 36(10): 13211334.

[16] Nikora, V. I., D. G. Goring, et al. (1998). "On gravel-bed roughness characterization." Water Resources Research 34(3): 517-527.

[17] Rapp, C., K. Eder, et al. (2012). 3D determination of the evolution of a scour hole by photogrammetric means. River Flow 2012. T. F. Group. London - England.

[18] Robert, A. (1988). "Statistical properties of sediment bed profiles in alluvial channels." Mathematical Geology. 20(3): 205-225.

[19] Smart, G., J. Aberle, et al. (2004). "Measurement and analysis of alluvial bed roughness." Journal of Hydraulic Research 42(3).

[20] Stojic, M., J. Chandler, et al. (1998). "The Assessment of Sediment Transport Rates by Automated Digital Photogrammetry." Photogrammetric Engineering \& Remote Sensing 64(5): 387-395.

[21] Zhang, Z. (1998). A Flexible New Technique for Camera Calibration, Microsoft Research. 